\title{
GPR56-Regulated Granule Cell Adhesion Is Essential for Rostral Cerebellar Development
}

\author{
Samir Koirala, ${ }^{1,2}$ Zhaohui Jin, ${ }^{4}$ Xianhua Piao, ${ }^{4}$ and Gabriel Corfas ${ }^{1,2,3}$ \\ ${ }^{1}$ F.M. Kirby Neurobiology Center, Children's Hospital Boston, Departments of ${ }^{2}$ Neurology and ${ }^{3}$ Otolaryngology, Harvard Medical School, and ${ }^{4}$ Division of \\ Newborn Medicine, Department of Medicine, Children's Hospital Boston and Harvard Medical School, Boston, Massachusetts 02115
}

\begin{abstract}
Mutations in GPR56, an orphan G-protein-coupled receptor (GPCR), cause bilateral frontoparietal polymicrogyria (BFPP), a disorder characterized by mental retardation, seizures, motor developmental delay, and ataxia. BFPP patients have structural abnormalities of the cerebral cortex, cerebellum, and pons. To shed light on the function of GPR56 and the anatomical and behavioral defects underlying BFPP, we analyzed the cerebellum of mice lacking this GPCR. Gpr56 $6^{-/-}$mice display a severe malformation of the rostral cerebellum that develops perinatally. Defects involve fusion of adjacent lobules, disrupted layering of neurons and glia, and fragmentation of the pial basement membrane. At the age of defect onset, GPR56 expression is restricted specifically to developing granule cells in the rostral cerebellum, suggesting that GPR56 regulates properties of these cells. Indeed, granule cells from the rostral region of perinatal $G p r 56^{-/-}$ cerebella show loss of adhesion to extracellular matrix molecules of the pial basement membrane. Interference RNA-mediated knockdown of GPR56 recapitulates the loss of adhesion seen in knock-outs, and reexpression of GPR56 rescues the adhesion defect in knock-out granule cells. Loss of GPR56 does not affect cell proliferation, migration, or neurite outgrowth. These studies establish a novel role for GPR56 in the adhesion of developing neurons to basal lamina molecules and suggest that this adhesion is critical for maintenance of the pia and proper cerebellar morphogenesis.
\end{abstract}

\section{Introduction}

Bilateral frontoparietal polymicrogyria (BFPP) is a congenital disorder whose clinical features include mental retardation, seizures, motor developmental delay, and nonprogressive ataxia (Harbord et al., 1990; Sztriha and Nork, 2000; Piao et al., 2002, 2005; Chang et al., 2003; Parrini et al., 2008). BFPP is caused by mutations in GPR56 (Piao et al., 2004), an orphan receptor of the poorly understood adhesion G-protein-coupled receptor (GPCR) family (Bjarnadóttir et al., 2007). BFPP patients have morphological abnormalities in multiple brain regions. Most studies have focused on the forebrain defects, which include abnormally small and irregular gyri and sulci, especially in the frontal lobe (Piao et al., 2002, 2004, 2005; Chang et al., 2003). However, magnetic resonance imaging has shown that BFPP patients also have hypoplasia of the cerebellum and pons (Chang et al., 2003; Piao et al., 2005). Although these gross morphological

Received March 11, 2009; revised April 15, 2009; accepted April 30, 2009.

This research was supported in part by National Institute of Neurological Disorders and Stroke Grants R01 NS35884 (G.C.) and K08 NS045762 and R01 NS057536 (X.P.), National Institutes of Health (NIH) Mental Retardation Research Center Grant P30-HD 18655 (G.C.), and Fundamental Neurobiology NIH Training Grant T32 NS007484-06 (S.K.). The Gpr56 knock-out mice, kindly provided by Genentech, were produced in a collaboration between Genentech and Lexicon Genetics to analyze the function of $\sim 500$ secreted and transmembrane proteins. We thank Dr. Rosalind Segal for the anti-Zic antibody, Dr. Richard Hynes for the anti-GPR56 antibody, Dr. Jane Johnson for the anti-Math1 antibody, Dr. Ulrich Mueller for the anti-integrin $\alpha 6$ antibody, and Dr. Azad Bonni for the GABA receptor $\alpha 6$ antibody. We thank Dr. Lihong Bu and Dr. Shihong Li for participation in initial experiments and Marcin Liana, Emily Chen, and Pieter Dikkes for technical assistance. We are also grateful to Dr. Kristine Roy and Dr. Joshua Murtie for helpful comments.

Correspondence should be addressed to Dr. Gabriel Corfas, F.M. Kirby Neurobiology Center, Children's Hospital Boston, 3 Blackfan Circle, CLS Room 12256, Boston, MA 02115. E-mail: gabriel.corfas@childrens.harvard.edu. DOI:10.1523/JNEUROSCI.1182-09.2009

Copyright $\odot 2009$ Society for Neuroscience $\quad$ 0270-6474/09/297439-11\$15.00/0 changes have been characterized, the specific histopathologies underlying BFPP and the developmental processes affected by GPR56 mutations have remained unknown.

Biochemical studies of GPR56 mutations that cause BFPP have suggested that they result in loss of function attributable to aberrant processing or trafficking of the protein (Jin et al., 2007; $\mathrm{Ke}$ et al., 2008). Consistent with these findings, Gpr56 knock-out mice exhibit forebrain defects with similarities to those seen in BFPP (Li et al., 2008). However, the cellular roles of GPR56 have remained unclear. Studies in vitro have shown that GPR56 overexpression inhibits the migration of telencephalic neural precursors (Iguchi et al., 2008), but the role of GPR56 in neuronal migration in vivo remains unknown. Based on the observation that GPR56 promotes (Shashidhar et al., 2005; Ke et al., 2007) or suppresses (Xu et al., 2006) cancer cell growth and spreading, it has also been proposed that GPR56 regulates cell adhesion, but this has remained untested in the nervous system.

In light of the severe motor phenotypes and apparent cerebellar abnormalities seen in BFPP patients, we studied the cerebellum of Gpr56 knock-out mice. We used histological, molecular, and behavioral approaches to characterize the defects caused by loss of GPR56 and also examined the potential cellular functions of this molecule in vitro and in vivo. Our experiments demonstrate that GPR56 is essential for proper morphogenesis of the rostral cerebellum and suggest that defects caused by loss of GPR56 arise from granule cell abnormalities in this region. Consistent with this hypothesis, developing granule cells from the rostral region of $G$ pr $56^{-/-}$cerebella at birth exhibit a specific defect in cell adhesion to extracellular matrix (ECM) molecules of the pial basement membrane (BM) but no defects in migra- 
tion, proliferation, or process outgrowth. These results support a novel hypothesis that the cerebellar defects in Gpr56 knock-outs, and potentially in human patients with GPR56 mutations, arise from the disrupted adhesion of developing granule cells to the pial BM.

\section{Materials and Methods}

Animals. Gpr56 knock-out mice on a mixed 129/BL6/FvB/BALB/c background were obtained from Genentech and Lexicon Genetics. The targeting scheme involved replacement of exons 2 and 3 of Gpr56 by IRESlacZ/MCI-neo, which results in the deletion of the starting ATG and causes a frame shift. Fetal stage was calculated from the day when a vaginal plug was observed [considered as embryonic day 0.5 (E0.5)]. Most litters were born on E20 or E20.5 [considered postnatal day 0 (P0) or P0.5, respectively]. All animals were treated according to the guidelines of the Animal Care and Use Committee of Children's Hospital Boston.

Antibodies. Immunolocalization was performed using the following antibodies: rabbit anti-Zic (1:400; a kind gift from Dr. Rosalind Segal, Harvard Medical School, Boston, MA), rabbit anti-GPR56 (1:100; a kind gift from Dr. Richard Hynes, Massachusetts Institute of Technology, Cambridge, MA), rabbit anti-Math1 (1:100; a kind gift from Dr. Jane Johnson, University of Texas Southwestern, Dallas, TX), mouse antiCalbindin (1:200; Sigma), rabbit anti-brain lipid binding protein (BLBP) (1:1000; Millipore Bioscience Research Reagents), guinea pig anti-glutamate-aspartate transporter (GLAST) (1:4000; Millipore Bioscience Research Reagents), rabbit anti-Engelbreth-Holm-Swarm laminin (1:40; Sigma), anti-GFAP (1:400; Dako), anti-GABA receptor $\alpha 6$ (1:200; a kind gift from Dr. Azad Bonni, Harvard Medical School, Boston, MA), antitubulin $\beta$ III (1:500; Sigma), rat anti-bromodeoxyuridine (1:400; Axyll), rabbit anti-GFAP (1:200; Dako), goat anti-collagen IV (1:25; Southern Biotechnology Associates), mouse anti-neuronal-specific nuclear protein (1:400; Millipore Bioscience Research Reagents), rat anti- $\alpha 6$ integrin (1:400; a kind gift from Dr. Ulrich Mueller, Scripps Research Institute, La Jolla, CA), and rat anti- $\beta 1$-integrin (1:200; Millipore Bioscience Research Reagents).

Interference RNA and expression vectors. Plasmids encoding small hairpin RNAs (shRNAs) along with enhanced green fluorescent protein (EGFP) were generated and tested as described in supplemental Materials and Methods (available at www.jneurosci.org as supplemental material). The Gpr56 shRNA targeted the sequence TAACTACGGCCCCATTATC, whereas the sequence for the scrambled, control shRNA was GCCCTCTACACTCTAAGTA. For GPR56 expression, plasmids encoding full-length GPR56 with fluorescent or nonfluorescent tags were generated and tested (supplemental Materials and Methods, available at www.jneurosci.org as supplemental material).

Histology and immunohistochemistry. Whole brains of embryos were immersion fixed in $4 \%$ paraformaldehyde in $0.1 \mathrm{~m}$ PBS. Postnatal mice were transcardially perfused with the same fixative. After $2 \mathrm{~h}$ to overnight immersion in the fixative at $4^{\circ} \mathrm{C}$, brains were rinsed in PBS and moved to $30 \%$ sucrose in PBS for cryoprotection. Brains were embedded in Tissue Tek OCT medium (Sakura) and cryosectioned at 12-16 $\mu \mathrm{m}$. Sections were stained with $0.1 \%$ cresyl violet $/ 0.5 \%$ acetic acid or processed for immunolabeling using standard procedures. Primary antibodies were visualized using appropriate fluorophore-conjugated secondary antibodies (1:200-1:400; Jackson ImmunoResearch). Nuclei were stained with $4^{\prime}, 6^{\prime}$-diamidino-2-phenylindole (DAPI) (Invitrogen). Sections were mounted in Gelmount (Biomeda) to inhibit photobleaching. Images were captured using a confocal LSM 510 NLO system (Zeiss) or a Spot digital camera (Diagnostic Instruments) on a Nikon 80i epifluorescence microscope. Levels were adjusted uniformly, and, in some cases, images of adjacent fields were stitched together in Photoshop (Adobe Systems). Numbering of cerebellar lobules was done as in the study by Sudarov and Joyner (2007). For measurements of midsagittal cerebellar area, images of three Nissl-stained midsagittal cerebellar sections from $\sim 50 \mu \mathrm{m}$ apart were used per animal. Regions of interest were traced, and the area was calculated in NIH ImageJ (Wayne S. Rasband, National Institutes of Health, Bethesda, MD).
In situ hybridization. In situ hybridization was performed essentially as described previously (Schaeren-Wiemers and Gerfin-Moser, 1993). Briefly, DNA templates for transcribing cRNA probes were generated by PCR using the following primer pairs: Gpr56, forward, 5'-ATTTAGGTGACACTATAGAAGTGGGTAGAAGCCACTCACAAACACTAC-3'; reverse, 5' -GCGTAATACGACTCACTATAGGGAGAAGGTTGAACAGGAACACCAGAC-3'; Blbp, forward, 5'-ATTTAGGTGACACTATAGAAGTGTGAGTACATGAAAGCTCTGG-3'; reverse, GCGTAATACGACTCACTATAGGGAGACTACCTCCACACCGAAGAC-3'; Math1, forward, 5' -ATTTAGGTGACACTATAGAAGTGAACGTTATCCCGTCCTTCAAC-3'; and reverse, 5'-GTAATACGACTCACTATAGGGAGAGGAAAACTCTCCGTCACTTCTG-3'.

Underlined regions correspond to SP6 (in forward primers) and T7 (in reverse primers) RNA polymerase binding sequences. Digoxigenin (DIG)labeled sense and antisense riboprobes were generated using SP6 and T7 polymerases, respectively (Promega) and a DIG-dUTP mix (Roche). DIGlabeled riboprobes were hybridized to 12 - to $16-\mu \mathrm{m}$-thick cryosections of embryonic mouse brain, detected using an alkaline phosphatase-conjugated anti-DIG antibody (Roche), and developed with a nitroblue-tetrazoliumchloride/5-bromo-4-chlor-indolyl-phosphate substrate (Roche).

Electron microscopy. Cerebella were removed from embryos and immersed overnight at $4^{\circ} \mathrm{C}$ in fixative containing $0.1 \mathrm{~m}$ sodium cacodylate, pH 7.2, 2.5\% glutaraldehyde, $2 \%$ paraformaldehyde, and 1\% acrolein. The cerebella were cut into two halves in the midsagittal plane and then osmicated, dehydrated, and embedded in epoxy. Sections of $1 \mu \mathrm{m}$ were cut from the midsagittal surface, stained with toluidine blue, and examined to identify the rostral cerebellum. Ultrathin sections were cut in the same plane and contained lobules I-III and IV-V as well as some adjacent tissue. Sections mounted on single slot grids were stained with uranyl acetate and lead citrate and imaged in either a Jeol 1200EX or Tecnai $\mathrm{G}^{2}$ Spirit BioTWIN electron microscope.

Adhesion assays. For adhesion assays with cells from freshly dissected brains, P0.5 litters consisting of Gpr56 $6^{+/-}$and $G p r 56^{-/-}$mice were used in each of four separate experiments (total $n=15 \mathrm{Gpr}^{56^{+/-}}$and 16 $\mathrm{Gpr}_{56}{ }^{-1-}$ animals). Experiments were performed blind, with genotyping performed afterward. Each brain was dissected into cold HBSS, the cerebellum was separated, and the overlying meninges were removed. The cerebellum was then microdissected to obtain the rostral and caudal regions. For the rostral, we cut the cerebellum at the primary fissure between lobules IV-V and lobule VI-VIII, thus obtaining rostral lobules I-III and IV-V. For the caudal portion, we cut at the middle of lobules VI-VIII and took tissue posterior to this, thus obtaining approximately lobules VII-X. In the mediolateral axis, the dissected pieces contained the vermis and medial regions of the hemispheres. The rostral and caudal cerebellar tissue from each mouse was processed separately. Tissues were minced and then incubated in $20 \mathrm{U} / \mathrm{ml}$ papain and $2000 \mathrm{U} / \mathrm{ml}$ DNase in $\mathrm{Ca}^{2+}$ and $\mathrm{Mg}^{2+}$-free HBSS containing $1 \mathrm{~mm} \mathrm{~L}$-cysteine and $0.5 \mathrm{~mm}$ EDTA for $15 \mathrm{~min}$ at $37^{\circ} \mathrm{C}$. The papain was inactivated by addition of high-glucose DMEM (Invitrogen) containing 10\% fetal bovine serum, and the tissue was gently triturated using fire-polished Pasteur pipettes of decreasing bore diameter. In some experiments, cells were mechanically dissociated in HBSS with $1 \mathrm{~mm}$ EDTA in the absence of papain and DNase ( $n=5 \mathrm{Gpr}^{+/-}$and $4 \mathrm{Gpr}^{+/-} 6^{-/}$animals). Cells were centrifuged at $750 \times g$ for $5 \mathrm{~min}$, after which the supernatant was aspirated and cells were resuspended in serum-free DMEM. This step was repeated to remove remaining serum. From the rostral and the caudal portions of the cerebellum of each mouse, 20,000 cells per well (in $150 \mu$ l of serum-free DMEM) were plated separately in triplicate onto wells of 48 -well polystyrene tissue culture plates (Corning Life Sciences) coated with $2 \mu \mathrm{g} / \mathrm{ml}$ mouse Engelbreth-Holm-Swarm laminin (laminin-1) (Sigma), $5 \mu \mathrm{g} / \mathrm{ml}$ human fibronectin (BD Biosciences), or $4 \mu \mathrm{g} / \mathrm{ml}$ collagen IV (BD Biosciences). Plates were placed in a $37^{\circ} \mathrm{C}$ tissue culture incubator for $2 \mathrm{~h}$ for laminin-1, $90 \mathrm{~min}$ for fibronectin, and $3 \mathrm{~h}$ for collagen IV. Substrate concentrations and incubation times were selected based on previous tests (data not shown) to allow detection of both increases and decreases in adhesion. Also, to minimize variability in adhesion assays, all samples and treatments in each experiment were run simultaneously. After incubation, unattached cells were gently removed, and the remaining adherent cells were fixed with $4 \%$ paraformaldehyde in PBS for $20 \mathrm{~min}$. Gran- 
ule cells adhered poorly to uncoated or $1 \%$ BSA-treated plates $(<6 \%$ at $2 \mathrm{~h}$ ). After fixation, cell nuclei were stained with DAPI. Cells were immunostained with Math1 and Zic for cells of the granule cell lineage and GFAP for glial cells. Images of 10 random fields were captured per well using a video camera (Hamamatsu), and cells were counted in NIH ImageJ. The corresponding cell counts from control wells (BSA-coated or uncoated) were subtracted for each sample.

For adhesion assays with cells from cultured slices, several modifications were made. Rostral regions of cerebella showing robust EGFP expression were separated with a scalpel and collected in cold HBSS. Digestion in papain was reduced to $10 \mathrm{~min}$, and trituration was also minimized because the cells dissociated more readily. Cells were centrifuged and resuspended in serum-free DMEM only once to minimize cell loss. The number of GFP-positive $\left(\mathrm{GFP}^{+}\right)$cells per milliliter was counted for each sample, and equal numbers of GFP ${ }^{+}$cells $(1500$ in $150 \mu \mathrm{l}$ ) were added to coated wells of 48 -well plates. Incubation, washes, fixation, staining, and imaging were performed as before. The number of $\mathrm{GFP}^{+}$cells per square millimeter was calculated for each sample. Because $\mathrm{GFP}^{+}$cells comprised only $\sim 8 \%$ of total cells added, the entire area of adherent cells was counted to avoid sampling error. Measurements in each experiment were normalized to controls $[n=$ 4 experiments for interference RNA (RNAi); $n=3$ experiments for GPR56 reexpression; $n=$ more than 3 slices per sample per experiment]. For all adhesion assays, data are expressed as mean \pm SEM and were evaluated by one-way ANOVA and Bonferroni's post hoc test using Prism software (GraphPad). Differences among groups were considered significant if $p<0.05$.

Electroporation and organotypic cultures. Freshly dissected brains from E18.5 embryos were embedded in 4\% low-melt agarose and placed on ice. Agarose blocks were trimmed to remove the forebrain, after which the brains were cut in half midsagittally. DNA plasmids $(\sim 2 \mathrm{mg} / \mathrm{ml})$ in PBS containing $0.01 \%$ fast green as a tracer were injected into the small space adjacent to the rostral cerebellum. The agarose was quickly trimmed further, and the block was electroporated with a BTX electroporator using paddle-style electrodes. Two $5 \mathrm{~ms}$ square pulses of $100-$ $120 \mathrm{~V}$ were used, similar to settings used for forebrain slice cultures (Stühmer et al., 2002). After electroporation, hindbrains were cut into $300-400 \mu \mathrm{m}$ sagittal slices on a vibratome (Leica) or tissue chopper, and slice cultures were prepared essentially as described previously (Englund et al., 2006). Briefly, slices were placed on Millicell cell culture inserts (Millipore Corporation) and grown at $37^{\circ} \mathrm{C}$ in DMEM with $10 \%$ fetal bovine serum, L-glutamine, penicillin, and streptomycin. In some cases, serum-free Neurobasal media (Invitrogen) with $\mathrm{N} 2$ and B27 supplements (Invitrogen) were used. Slices were kept in culture for $24-48 \mathrm{~h}$.

Behavioral assay. The rotating rod and balance beam tests of motor coordination were performed essentially as described previously (Carter et al., 1999). All behavioral tests and scoring were performed blind to genotype. Briefly, for the rotarod test, the mice were trained at 8,16 , and $20 \mathrm{rpm}$ on 3 consecutive days. At each session, mice were allowed to acclimatize to the procedure room for $60 \mathrm{~min}$. On subsequent days, they were tested on an accelerating rotarod starting at $8 \mathrm{rpm}$ and reaching 40 $\mathrm{rpm}$ at $1 \mathrm{rpm} / \mathrm{s}$. The length of time to a maximum of $60 \mathrm{~s}$ that the mice stayed on the rod were recorded and averaged over sessions. For the balance beam test, mice were trained in three trials to walk on a wide (20 $\mathrm{mm}$ width $\times 1 \mathrm{~m}$ length) balance beam. All the mice traversed the wide beam without making errors (foot slips). The mice were then trained on a narrow ( $4 \mathrm{~mm}$ width $\times 1 \mathrm{~m}$ length) beam for three trials. At the end of the training trials, no freezing behavior was observed, and the mice would start to walk within $4 \mathrm{~s}$ of being placed on the beam. The mice were then videotaped as they performed three test trials of three beam walks each, for a total of nine walks per mouse. The three trials were performed on separate days. Videotaped walks were scored for number of foot slips (errors) and time to cross. Data are expressed as mean \pm SEM and were evaluated by unpaired one-tailed Student's $t$ test. Differences among genotypes were considered significant if $p<0.05$.

\section{Results \\ $\mathrm{Gpr}^{-1-}$ mice have morphological defects in the rostral cerebellum}

Gpr56 ${ }^{-1-}$ mice were provided by Genentech and Lexicon Genetics. In these mice, exons 2 and 3 of Gpr56 have been eliminated, resulting in deletion of the starting ATG and the consequent loss of GPR56 expression as determined by reverse transcription-PCR and Western blot (Li et al., 2008). Gpr56 $6^{-/-}$mice are born in normal Mendelian ratios and are indistinguishable from wild types in their gross behavior, including feeding, grooming, and reproduction.

Because abnormalities of the cerebellum and pons have been observed in humans carrying GPR56 mutations, we analyzed cerebellar and pontine morphology in $G p r 56^{-/-}$mice. Histological analysis of adult mice showed that cerebellar morphology was normal in heterozygotes but that the rostral part of the cerebellum, encompassing lobules I-V, was malformed in all homozygotes (Fig. 1A) $(n=14)$. The defects, which included fusion of adjacent lobules, disruption of normal layering, and ectopic clusters of neurons, spanned the entire mediolateral axis of the rostral cerebellum, including the vermis as well as cerebellar hemispheres (Fig. $1 A$, bottom row). In the pons, the defect primarily involved loss of neurons in the pontine gray nuclei (supplemental Fig. S1, available at www.jneurosci.org as supplemental material).

To define the nature of the alterations that occur in the affected cerebellar lobules, we stained the tissue with markers for granule cells (Zic), Purkinje cells (Calbindin), and Bergmann glia and astrocytes (GLAST), as shown in Figure $1 B$. In the adult, within the affected lobules, the positioning of all these cell types is disrupted in the absence of GPR56. Cell ectopias contained granule cells (Fig. $1 B$, top middle, arrowheads) and Purkinje cells (Fig. $1 B$, top right, asterisk). Bergmann glia and their processes appeared mislocalized and disorganized as well (Fig. $1 B$, bottom middle, arrowheads). Magnified views of $G p r 56^{+/-}$(Fig. 1C, left column) and $G p r 56^{-/-}$(Fig. 1C, right column) cerebella illustrate the defects seen in the knock-out, including ectopic clusters of granule cells (Fig. 1C, top right, arrowheads), disrupted Bergmann glial arborization (Fig. $1 C$, middle right, arrowheads), and misoriented Purkinje cells (Fig. 1C, bottom right, asterisks). As shown in Figure $1 D$, the disorganization of the glial scaffold is particularly clear using GFAP immunostaining: whereas Bergmann glial processes in $G p r 56^{+/-}$cerebella exhibit normal radial morphology (arrows in left), these processes appear in clumps and project in arbitrary directions (arrows in right) in the affected regions of $G p r 56^{-/-}$cerebella.

\section{Cerebellar defects in Gpr56 knock-outs originate perinatally}

To determine the time at which the malformation arises, we examined $G$ pr56 ${ }^{-1-}$ mice at younger ages (E12.5-E18.5). Even as late as E18.5 (supplemental Fig. S2, available at www. jneurosci.org as supplemental material), Gpr56-/- cerebellar morphology appeared remarkably normal, with all observed cell types and BM indistinguishable from heterozygotes. However, by birth (P0.5), cerebella in Gpr56 $6^{-1-}$ mice displayed obvious abnormalities in the rostral region. Nissl stain (Fig. 2A) showed defects in the organization of the rostral lobules, especially developing lobules I-III, in the Gpr56 $6^{-/-}$mice. Immunostaining for GLAST and Zic demonstrated that Bergmann glia as well as granule cells were already affected at this stage. GLAST staining showed that glial processes in the affected region were often misoriented and that the glia limitans formed by the Bergmann glial end feet appeared ruptured in multiple locations (Fig. 2C, bottom, arrowheads), with glial processes often extending outside 
A

$$
\text { Gpr56 +/- }
$$
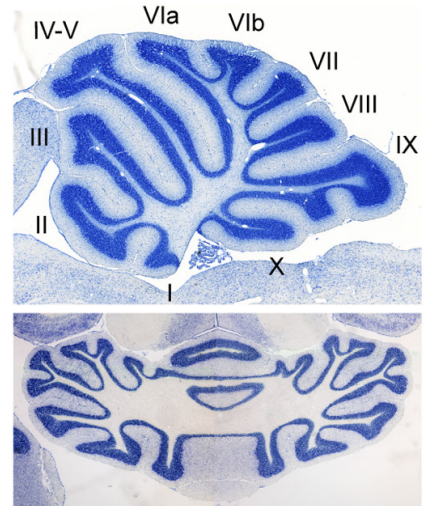

C

Gpr56 +/-

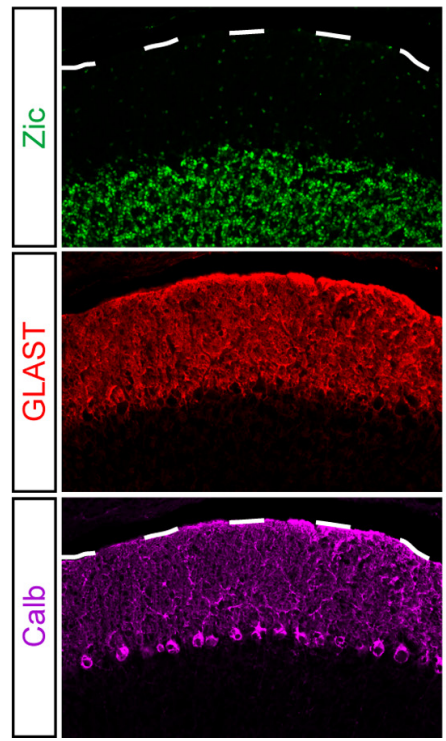

Gpr56 -/-

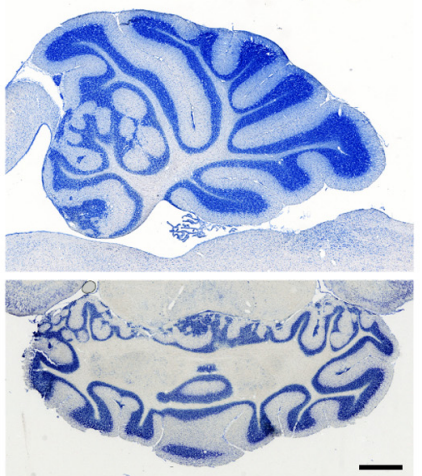

Gpr56 -/-

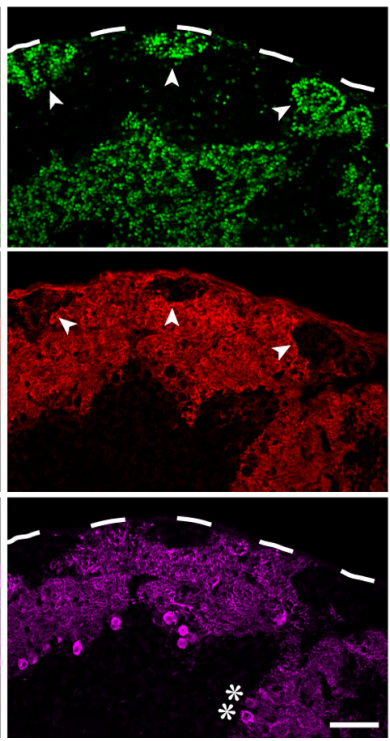

B

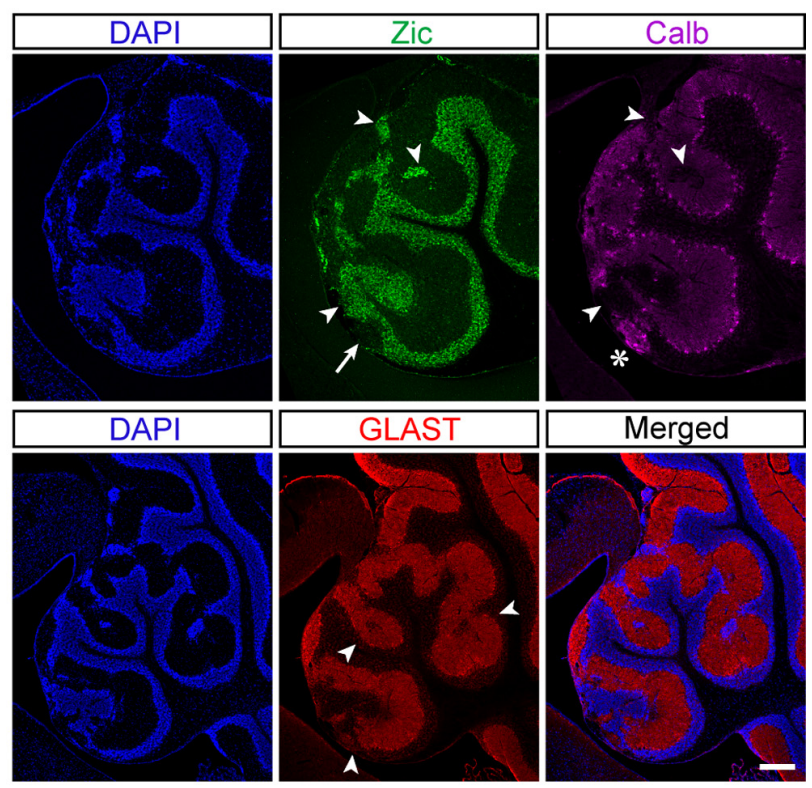

D

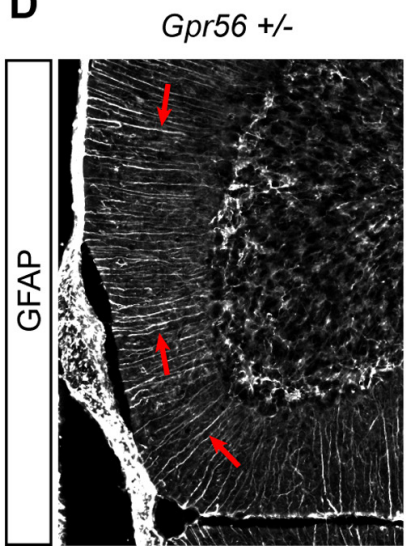

Gpr56 -/-

Gpr56 -/-

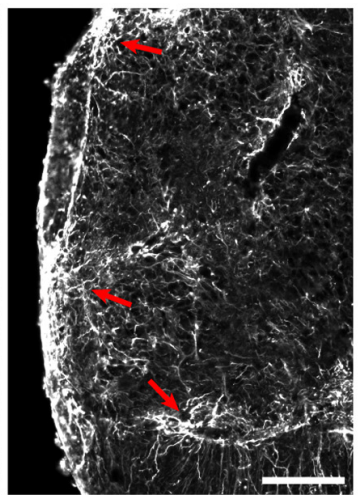

Figure 1. Rostral cerebellar defects in adult Gpr56 ${ }^{-1-}$ mice. $A$, Top row, Midsagittal Nissl-stained sections of adult cerebella reveal a striking defect in the rostral cerebellar region (lobules I-V) in Gpr56 $6^{-/-}$mice, including fusion of lobules I-III, whereas the caudal region appears normal. Heterozygous mice are unaffected. Bottom row, Horizontal sections illustrate that the defects in the $\mathrm{Gpr}_{56^{-/-}}$cerebellum extend along the entire mediolateral axis. $\boldsymbol{B}$, Top row, Low-magnification views of the most severely affected lobules (I-III) in the Gpr $56^{-/-}$adult cerebellum with staining for cell nuclei (DAPI), granule cells (Zic), and Purkinje cells (Calbindin) show that layering of both neuronal types is disrupted in $\mathrm{Gpr}_{56^{-1}}{ }^{-}$mice. Immunostaining with Zic (arrowheads, middle) and GABA receptor $\alpha 6$ (data not shown) indicates that most ectopic cells are differentiated granule cells, but ectopic Purkinje neurons are also seen (asterisk, right). Despite defects in overall cellular architecture, the normal segregation between neuronal types is preserved, with ectopic granule cells and Purkinje cells showing little overlap (arrow, arrowheads, and asterisk in middle and right). Bottom row, Immunostaining for the glial marker GLAST shows that the Bergmann glial scaffold is also severely disorganized in the mutant mice (arrowheads, middle). C, Magnified views of lobule II from Gpr56 $6^{+/-}$(left column) and lobules I-III from Gpr56 $6^{-/-}$(right column) cerebella illustrate the multiple cell defects, including ectopic granule cell clusters (arrowheads in top right), Bergmann glial arborization that terminates at the ectopias rather than at the pia (arrowheads in middle right), and misoriented Purkinje cells (asterisks in bottom right). $\boldsymbol{D}$, Immunostaining for GFAP reveals the orderly radial scaffold of Bergmann glial fibers (arrows in left) in lobule III of the Gpr $56^{+/-}$cerebellum. In contrast, in lobules I-III of the Gpr $56^{-/-}$cerebellum, the glial scaffold is severely disorganized, with clumps of Bergmann glial processes extending in arbitrary directions (arrows in right). Scale bars: $A, 500 \mu \mathrm{m} ; \boldsymbol{B}$, top row, $200 \mu \mathrm{m} ; \boldsymbol{B}$, bottom row, $250 \mu \mathrm{m} ; \boldsymbol{C}, 60 \mu \mathrm{m} ; \mathbf{D}, 80 \mu \mathrm{m}$.

the cerebellum (Fig. 2C, bottom, asterisk). Zic-positive granule cells were present in ectopic locations outside the disrupted pial membrane (Fig. $2 D$, bottom, arrows). Consistent with the alteration in the glia limitans, staining for laminin-1 indicated that the $\mathrm{BM}$ lining the cerebellum was fragmented selectively in the affected lobules (Fig. 2E, bottom). Similar results were obtained with collagen IV staining (data not shown).

Because the phenotype was dramatic at P0.5, we hypothesized that subtle defects could already be present at earlier ages. Therefore, we used electron microscopy to examine the pial BM and external granule layer (EGL) at E18.5-E19.5. Most of the rostral cerebellum in Gpr56 knock-outs appeared normal at these ages. However, as shown in Figure 2F, at E19.5, we observed some focal ruptures of the BM (break in the dotted line), which were associated with what appeared to be granule cell precursors migrating outward (arrowheads). At E18.5, we noticed a few instances of single granule cells that appeared to be breaching the BM (data not shown). These results indicate that, at E18.5 to P0.5, the interactions between granule cells and the BM are disrupted in the $G \mathrm{pr} 56^{-/-}$rostral cerebellum.

Perinatally, GPR56 is expressed by developing granule cells in the rostral cerebellum

To gain insight into why the defects in $G p r 56^{-/-}$mice are limited to the rostral cerebellum, we examined the pattern of expression of GPR56 in wild-type mice using in situ hybridization and im- 
A
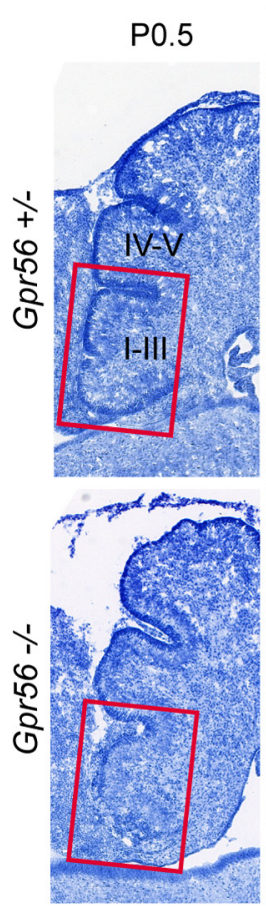

B
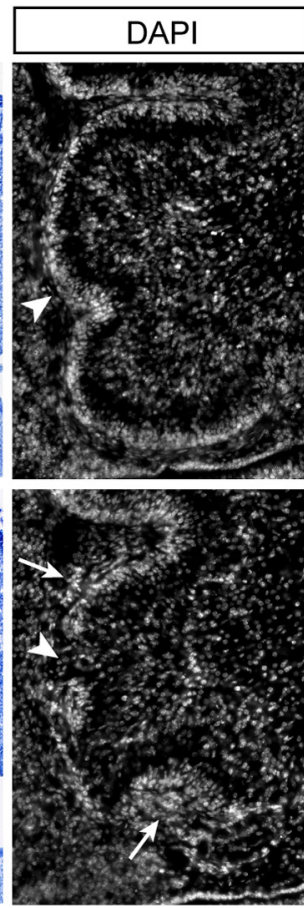

C
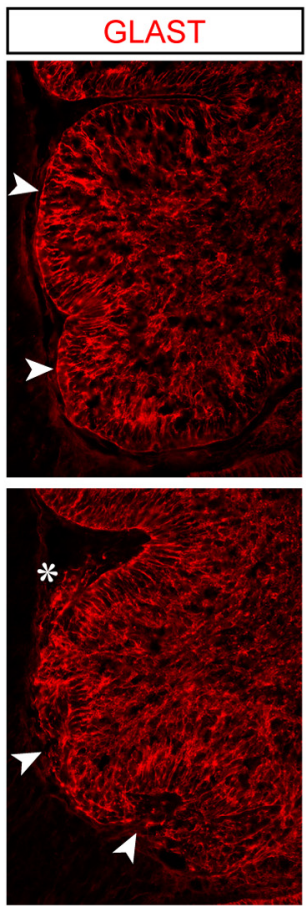

D
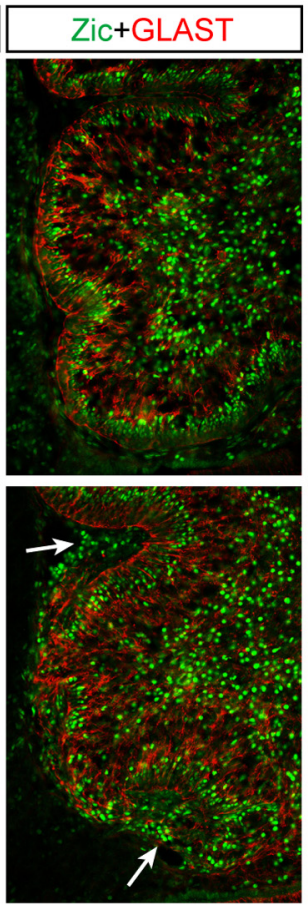

E
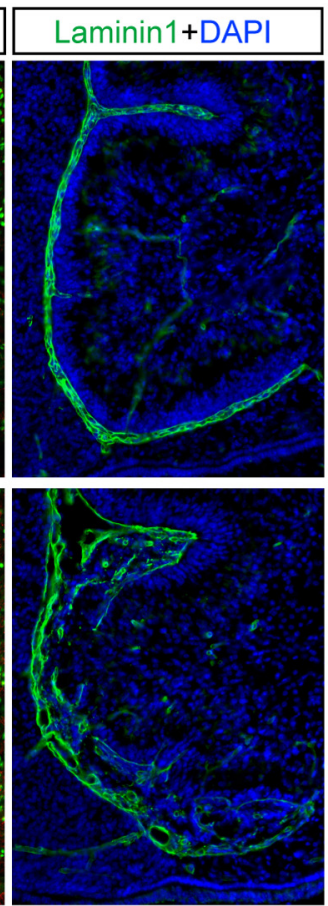

F E19.5
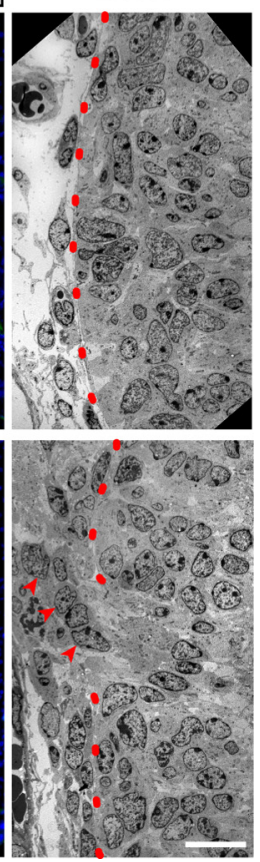

Figure 2. Cerebellar defects in Gpr56 knock-outs originate perinatally and affect BM integrity. A, Nissl-stained midsagittal sections of Gpr56 ${ }^{+/-}$(top) and Gpr56 ${ }^{-/-}$(bottom) cerebella at P0.5 show defects in the rostral region in homozygotes, with lobules I-III most severely affected. $\boldsymbol{B}-\boldsymbol{E}$, Analysis of cerebellar lobules I-III of P0.5 Gpr56 ${ }^{+/-}$(top) and Gpr56 ${ }^{-/-}$(bottom) mice by immunostaining. $\boldsymbol{B}$, Nuclear staining (DAPI) shows that, whereas in heterozygotes the EGL is a continuous layer of cells (top, arrowhead), in homozygotes the EGL is interrupted (bottom, arrowhead), and clusters of ectopic cells (bottom, arrows) are seen outside the EGL. C, Staining with the glial marker GLAST (red) shows that the glia limitans formed by Bergmann glia end feet (top, arrowheads) is disrupted in the homozygote (bottom, arrowheads). Bergmann glial processes can also be seen aberrantly projecting outside the cerebellum (bottom, asterisk). $\boldsymbol{D}$, Immunostaining for the granule cell marker Zic (green) and GLAST (red) shows that the ectopic cells located outside the cerebellar wall are predominantly postmitotic granule cells (bottom, arrows). $\boldsymbol{E}$, Immunostaining for laminin-1 (green), a major component of the pial BM overlying the cerebellum, shows that the BM is intact in heterozygotes (top) but severely fragmented in homozygotes (bottom). $\boldsymbol{F}$, Electron microscopy of lobules I-III in E19.5 cerebella shows the earliest detectable defects: whereas Gpr56 ${ }^{+/-}$mice have a well organized EGL and intact cerebellar wall (dashed line in top), in Gpr56 ${ }^{-/-}$cerebella, small ruptures in the BM can be observed (interruption in dashed line, bottom) with putative granule cells (arrowheads) found outside the cerebellum. Scale bar: (in $\boldsymbol{F}$ ) $\boldsymbol{A}, 250 \mu \mathrm{m} ; \boldsymbol{B}-\boldsymbol{E}, 100 \mu \mathrm{m} ; \boldsymbol{F}, 15 \mu \mathrm{m}$.

munocytochemistry (Fig. 3). At perinatal age, when the phenotype becomes evident, GPR56 expression is restricted to the rostral cerebellum (Fig. $3 A, B$ ), in striking correspondence with the region affected in $G$ pr $56^{-/-}$mice. These findings suggest that the spatially restricted nature of the anatomical phenotype is a consequence of the restricted pattern of GPR56 expression. The findings also highlight the narrow time window in which GPR56 appears to be critical in the rostral cerebellum (between approximately E18.5 and P0.5) because defects are not observed before E18.5 (supplemental Figs. S2, S3, available at www.jneurosci.org as supplemental material), and all knock-outs exhibit defects by P0.5. Moreover, despite the expansion of GPR56 expression to the caudal cerebellum by $\mathrm{P} 7$ (Fig. $3 E$ ), the affected region remains restricted to lobules $\mathrm{I}-\mathrm{V}$ at all ages after P0.5, suggesting that GPR56 is not required in the same manner after perinatal age.

In situ hybridization also showed that, at E19.5, Gpr56 mRNA is restricted to the EGL of the rostral cerebellum (Fig. $3 A$, left and middle). Gpr56 expression does not overlap with that of Blbp (Fig. $3 A$, right), a glial marker, indicating that, at this age, Bergmann glia do not express Gpr56. Gpr56 mRNA is also absent in meningeal cells (Fig. $3 A$, middle, arrowheads). Immunostaining confirmed that GPR56 expression is restricted to the rostral EGL in wild-type cerebellum at P0.5 (Fig. 3B) and not detected in Bergmann glia or Purkinje cells (Fig. 3C). As expected, GPR56 immunostaining is absent in knock-outs (Fig. 3B). Unlike Math1, which is specific to granule cell precursors in the outer EGL, GPR56 is present throughout the width of the EGL (Fig. 3D). These results collectively suggest that, perinatally, GPR56 func- tion is specific to developing granule cells (precursors and young postmitotic neurons) of the rostral cerebellum.

Importantly, although GPR56 is expressed in granule cell precursors in the rhombic lip and the developing cerebellar anlage at earlier embryonic stages (E12.5 and E15.5 shown in supplemental Fig. S3A, available at www.jneurosci.org as supplemental material), we found no alteration in the granule cell precursor population or in cerebellar phenotype in $G p r 56^{-/-}$mice at these ages (supplemental Fig. S3B, available at www.jneurosci.org as supplemental material; also data not shown). These results indicate that GPR56 is dispensable for the initial generation and migration of granule cell precursors.

\section{Absence of GPR56 causes loss of adhesion of rostrally derived granule cells to $\mathrm{BM}$ molecules}

Based on the observation that the cerebellar defects in knock-outs are restricted to the region in which GPR56 is expressed perinatally and that GPR56 expression is specific to developing granule cells, we hypothesized that this cell population could be specifically affected by perinatal loss of GPR56. The biological roles of GPR56 are primarily unknown, but its sequence puts it within the "adhesion" subfamily of GPCRs (Bjarnadóttir et al., 2007) and it has been hypothesized to play a role in adhesion of cancer cells (Shashidhar et al., 2005; Ke et al., 2007). Therefore, we used a well characterized cell adhesion assay to test the attachment of freshly dissociated granule cells to three major components of the pial BM lining the cerebellum: laminin-1, fibronectin, and collagen IV (Sievers et al., 1994b). We compared cells from rostral and 
A

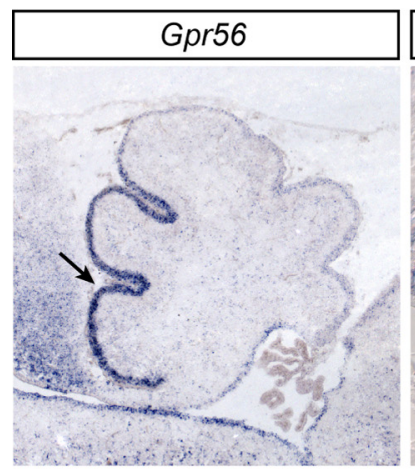

E19.5

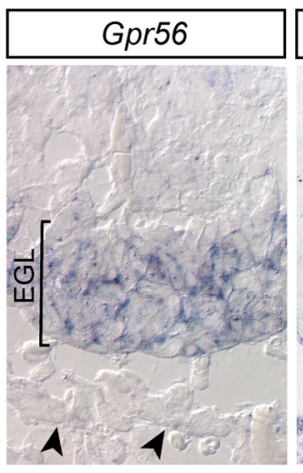

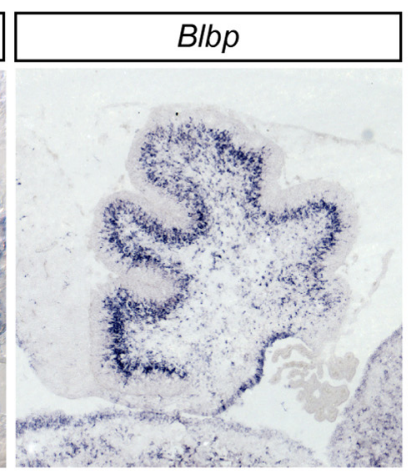

B

P0.5

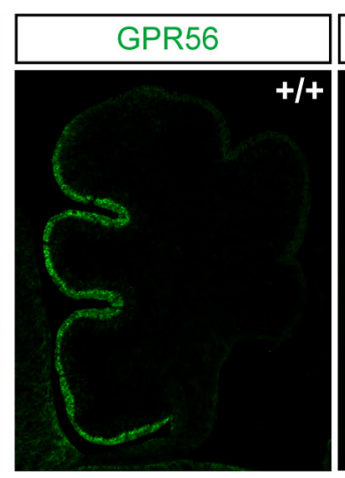

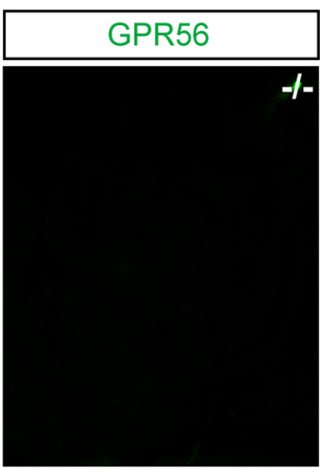

P7
C

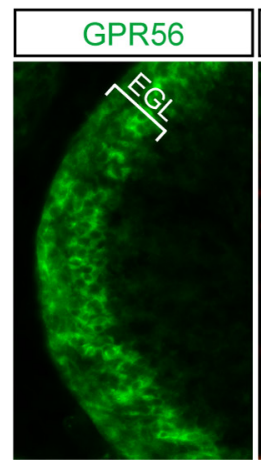

P0.5

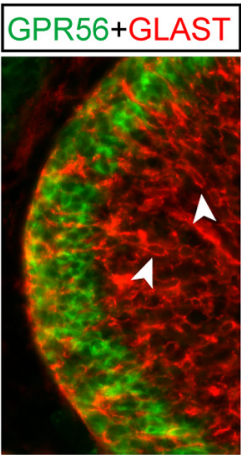

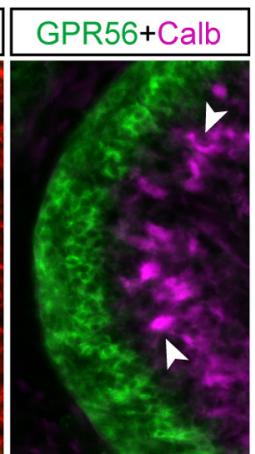

D

P0.5

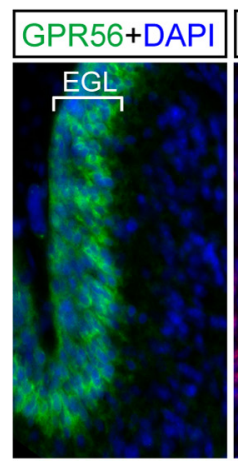

E

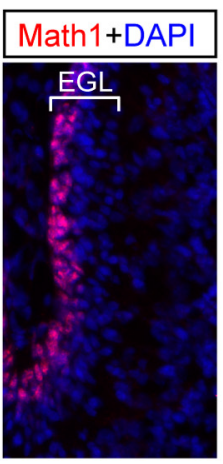

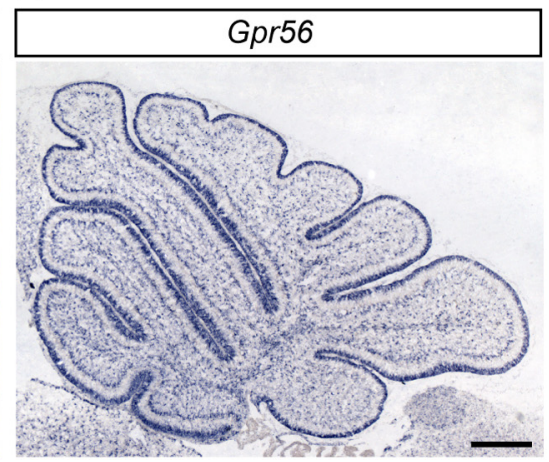

Figure 3. GPR56 is expressed perinatally in developing granule cells of the rostral cerebellum. $A$, Left, In situ hybridization for Gpr56 in a midsagittal section of wild-type cerebellum shows that, at E19.5, Gpr56 mRNA expression is restricted to the rostral region. Arrow marks area shown in middle. Middle, Magnified view of E19.5 lobules I-III shows that Gpr56 is expressed only in the EGL and not in deeper layers or in the meninges (arrowheads). Right, In situ hybridization on an adjacent section with a Blbp probe, which labels Bergmann glia and astrocytes, underscores the observation that Gpr56 is not detected in Bergmann glia at this age. $\boldsymbol{B}$, Localization of GPR56 protein parallels mRNA expression and is predominantly in the rostral cerebellum at birth. There is no expression in the Gpr56 ${ }^{-/-}$cerebellum. C, Magnified views demonstrate that GPR56 is in the EGL, consistent with expression in developing granule cells. Expression does not match the pattern seen for processes or cell bodies of GLAST-labeled Bergmann glia (in red; arrowheads mark cell bodies) or Purkinje cells (in magenta; arrowheads mark cell bodies). $\boldsymbol{D}$, GPR56 has broader expression across the EGL than Math1, a marker of granule cell precursors, indicating that GPR56 is expressed by precursors as well as young postmitotic granule cells. $E$, In situ hybridization shows that, by P7, Gpr56 expression is essentially uniform throughout the cerebellum. Scale bar: (in $\boldsymbol{E}) \boldsymbol{A}$, left and right, $350 \mu \mathrm{m} ; \boldsymbol{A}$, middle, $20 \mu \mathrm{m} ; \boldsymbol{B}, 300 \mu \mathrm{m} ; \boldsymbol{C}, \boldsymbol{D}, 40 \mu \mathrm{m} ; \boldsymbol{E}, 450 \mu \mathrm{m}$.

caudal cerebella of $\mathrm{Gpr} 56^{+/-}$and $\mathrm{Gpr} 56^{-/-}$mice to determine whether any alteration in the knock-outs is specific to cells from the rostral cerebellum. Rostrally and caudally derived granule cells from $G$ pr56 $6^{+/-}$cerebella and caudally derived cells from Gpr $56^{-/-}$cerebella adhered equally. In contrast, rostrally derived granule cells from the knock-outs showed significantly reduced adhesion to laminin-1 and fibronectin (Fig. 4). Adhesion to collagen IV was unaltered in the knock-out granule cells, suggesting that GPR56 regulates adhesion to specific basal lamina substrates. Importantly, rostrally derived glial cells showed no difference in adhesion (Fig. 4), indicating that the defect in adhesion was specific to granule cells. Furthermore, granule cell proliferation in vivo and migration and neurite outgrowth in vitro were indistinguishable between $G$ pr $56^{+/-}$and $\mathrm{Gpr}^{-1-}$ granule cells from the rostral cerebellum (supplemental Fig. S4, available at www. jneurosci.org as supplemental material), supporting the hypothesis that the critical defect in $G p r 56^{-/-}$cerebella is specifically in granule cell adhesion.

\section{RNAi-mediated knockdown of GPR56 recapitulates loss of}

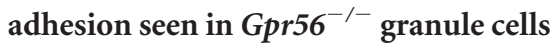

To further examine the role of GPR56 in granule cell adhesion, we tested the effects of gene knockdown using RNAi. Freshly dissected E18.5 Gpr56 ${ }^{+/-}$hindbrains were electroporated with an shRNA construct that effectively knocks down GPR56 expression (supplemental Fig. S5A, available at www.jneurosci.org as sup- plemental material). As controls, other hindbrains were electroporated with either the vector alone or a plasmid expressing a scrambled control shRNA. The vector also confers GFP expression to transfected cells. Tissues were then sliced sagittally, and slices containing the cerebellum were maintained in culture for $48 \mathrm{~h}$ to allow for protein knockdown. This approach resulted in robust and widespread transfection in the rostral cerebellum, as shown by GFP expression (supplemental Fig. S5C, available at www.jneurosci.org as supplemental material). The rostral cerebella were then isolated from the slices and subjected to gentle dissociation, and granule cells were tested for adhesion to fibronectin or laminin-1. More than $95 \%$ of the electroporated cells were granule cells (based on combined Math1 and Zic labeling; data not shown). Staining for GPR56 showed that the shRNA effectively knocked down GPR56 protein levels in the transfected cells (Fig. 5A, arrows). Whereas the vector alone and the scrambled shRNA construct did not alter cell adhesion, the Gpr56 shRNA significantly reduced the number of cells adhering to fibronectin or laminin-1 (Fig. 5B). Similar results were obtained when tissues from wild-type mice were used (data not shown).

\section{GPR56 reexpression in $G p r 56^{-/-}$granule cells rescues adhesion to BM molecules}

To further investigate the importance of GPR56 in granule cell adhesion, we tested whether the adhesion defects observed in Gpr $56^{-/-}$granule cells could be rescued by reexpression of the 
A

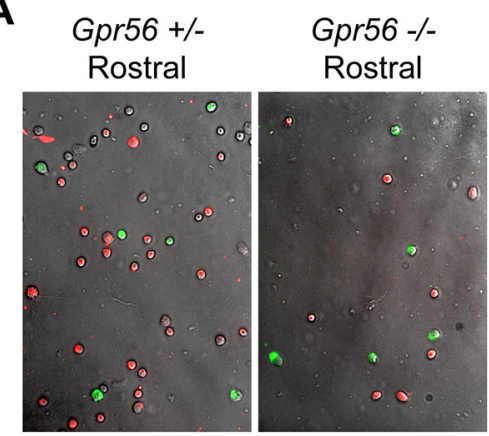

RED: Zic + Math1, GREEN: Gfap

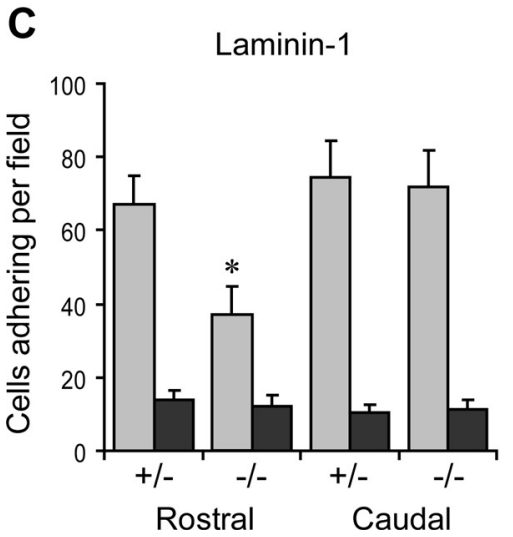

B

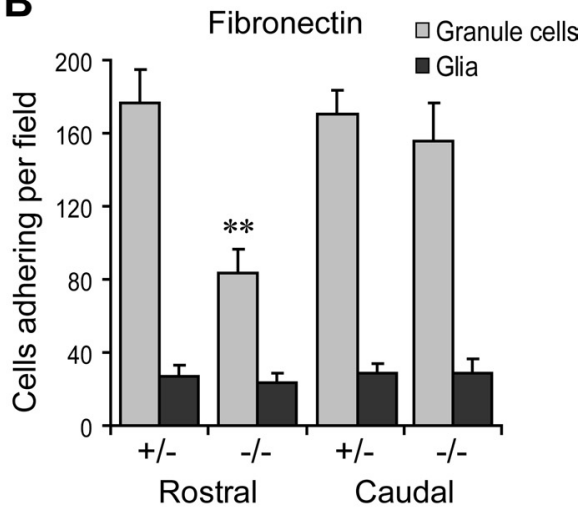

D

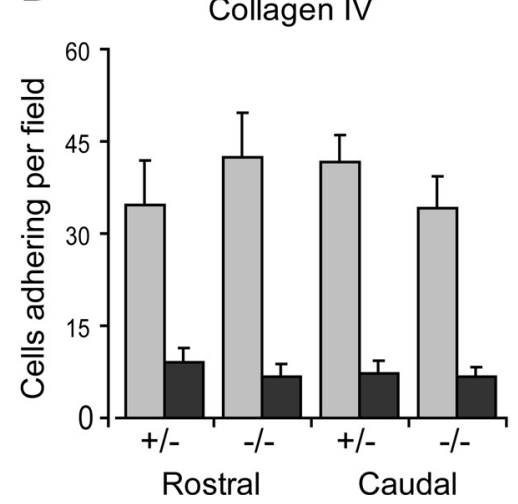

Figure 4. Granule cells from the rostral region of $\mathrm{Gpr} 56^{-1-}$ cerebella have defects in adhesion to fibronectin and laminin-1. Freshly dissociated cells from the rostral or caudal cerebellum of $G \mathrm{pr} 56^{+/-}$or $\mathrm{Gpr} 56^{-/-}$brains were plated onto tissue culture dishes coated with fibronectin, laminin-1, or collagen IV. After an incubation period, dishes were washed gently, cells were fixed and stained, and the numbers of granule cells or glial cells remaining adherent were measured. $\boldsymbol{A}$, Images from a fibronectincoated dish showing adherent granule cells (red) and glia (green) derived from rostral cerebella of $G \mathrm{pr} 56^{+/-}$(left) and Gpr56 $6^{-/-}$ (right) mice. Data from caudal cerebella of both genotypes were similar to the left (data not shown). $\boldsymbol{B}-\boldsymbol{D}$, Quantification of the adhesion assays on the three ECM substrates $\left({ }^{*} p<0.05\right.$ for laminin-1; ${ }^{* *} p<0.01$ for fibronectin; ANOVA; $n=4$ experiments; total $n=15 \mathrm{Gpr} 56^{+/-}$and $16 \mathrm{Gpr} 56^{-1-}$ animals).

wild-type gene product. Tissues from $G p r 56^{-/}$or wild-type mice were electroporated as described above with a plasmid encoding full-length epitope-tagged (V5-His at the $\mathrm{C}$ terminus) mouse GPR56 and a plasmid encoding GFP. Twenty-four hours later, cells from rostral cerebella were dissociated and subjected to adhesion assays. Immunostaining of the cells with an antibody to the V5 tag (Hearps et al., 2007) showed that $>97 \%$ of GFP ${ }^{+}$cells expressed the GPR56 protein (Fig. 5C). Similar results were obtained with a GPR56 antibody (data not shown). Therefore, we quantified the adhesion of GFP ${ }^{+}$cells to laminin- 1 and fibronectin and found that, whereas $G$ pr $56^{-/-}$granule cells from slice cultures transfected only with GFP displayed loss of adhesion similar to $G p r 56^{-1-}$ cells freshly obtained from live animals, the expression of full-length GPR56 rescued adhesion to levels similar to those observed in wild-type cells (Fig. 5D).

Together, these loss- and gain-of-function experiments in vitro demonstrate a critical role for GPR56 in granule cell adhesion and indicate that the loss of adhesion in rostrally located granule cells of $G p r 56^{-1-}$ mice is not simply a secondary consequence of the absence of GPR56 during development. Our study also suggests that GPR56 does not mediate cell adhesion through direct binding to ECM molecules, because neither addition of soluble GPR56 to the medium in the granule cell adhesion assay nor overexpression of full-length mouse GPR56 in a cell line (HEK 293T) altered cell adhesion to laminin-1 and fibronectin (supplemental Fig. S6, available at www. jneurosci.org as supplemental material). We also considered the alternative that GPR56 could affect adhesion by regulating expression of integrin receptors for laminin- 1 and fibronectin in the cerebellum. To test this possibility, we compared the patterns and levels of expression of integrin subunits $\alpha 3, \alpha 5, \alpha 6, \alpha 7$, and $\beta 1$ (the latter being an obligatory component of the main receptors for the three ECM molecules used in our study) in Gpr56 $6^{+/-}$and Gpr56 ${ }^{-1}$ cerebella by immunostaining and/or in situ hybridization. We found no conclusive differences in integrin expression between $\mathrm{Gpr} 56^{+/-}$and $\mathrm{Gpr} 56^{-/-}$cerebella (data not shown), suggesting that the loss of adhesion is not attributable to altered levels of these integrin receptors.

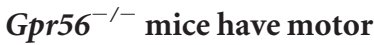 coordination deficits}

In light of the cellular and anatomical defects in $G$ pr $56^{-1-}$ mice and the prevalence of ataxia in BFPP patients, we examined motor function in $G p r 56^{-1-}$ mice. These mice did not exhibit obvious ataxia or gait abnormalities during normal behavior. Gpr $56^{-/-}$mice also performed equally as well as heterozygotes on a rotarod test (data not shown) and on a wide $(20 \mathrm{~mm}$ width) balance beam (crossing time, $12.3 \pm 2.4 \mathrm{~s}$ and foot slips, 0 for $G$ pr $56^{-/-}$; crossing time, $11.6 \pm 1.8 \mathrm{~s}$ and foot slips, 0 for $\mathrm{Gpr}^{2} 6^{+/-} ; n=9 \mathrm{Gpr} 56^{-1-}, 7$ $\mathrm{Gpr} \mathrm{6}^{+/-}$animals). However, when placed on a more challenging narrow beam (4 $\mathrm{mm}$ width), differences were readily apparent: Gpr56 knock-outs exhibited almost threefold more foot slips as heterozygotes and took twice as long to cross the beam (Fig. 6A) (supplemental Movie 1, available at www. jneurosci.org as supplemental material). Therefore, Gpr56 ${ }^{-1-}$ mice have modest but significant motor impairment that does not affect normal locomotor behavior but becomes evident when they are challenged. Interestingly, histological analysis of the mice that had been subjected to the behavioral tests showed a clear correlation between the severity of the behavioral deficit and the extent of the cerebellar malformation (Fig. $6 B, C$ ). As mentioned above, $\mathrm{Gpr} \mathrm{6}^{-1-}$ mice also have defects of the pons and, as described previously, of the cerebral cortex (Li et al., 2008). However, unlike with the cerebellum, the extent of the defects in these brain regions did not correlate with the severity of the behavioral phenotype (data not shown). Moreover, there was no clear correlation between the severity of the histological defects in the pons and cerebellum (data not shown), suggesting that the defects in the two areas arise independently. Taken as a whole, these results suggest that the rostral cerebellar defects are the primary cause of the motor deficit.

\section{Discussion}

The cerebellar phenotype of $G$ pr56 $6^{-1-}$ mice provides new insights into the cellular roles of this orphan GPCR and potential mechanisms involved in the pathogenesis of BFPP. The pattern of GPR56 expression together with the nature of the defects in 
A
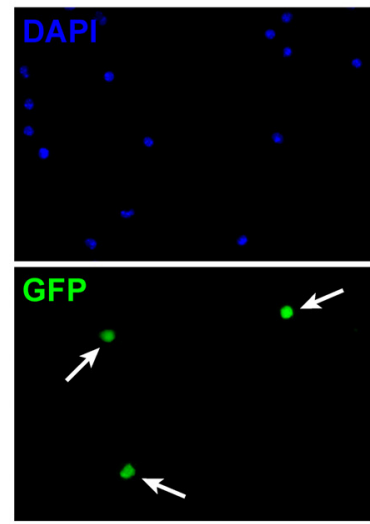

C
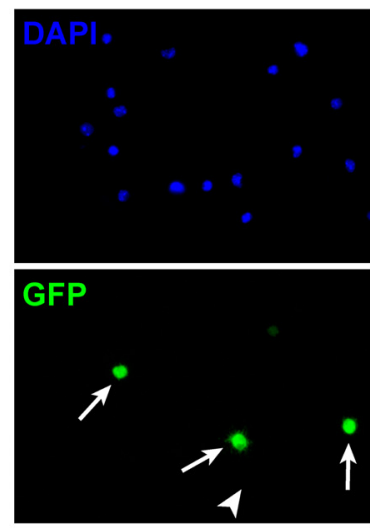
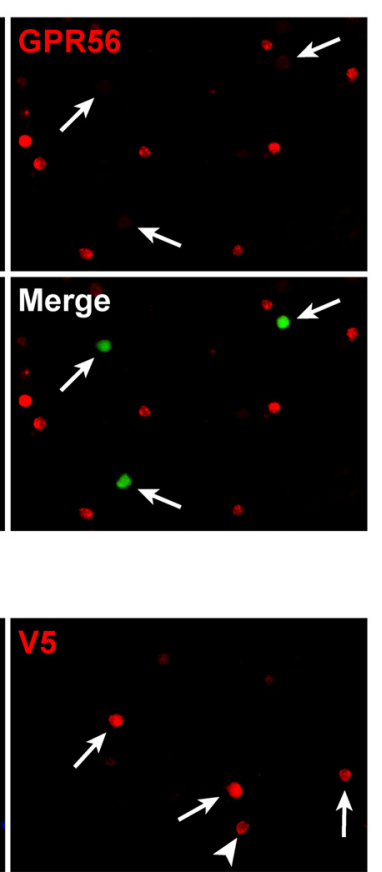

Merge

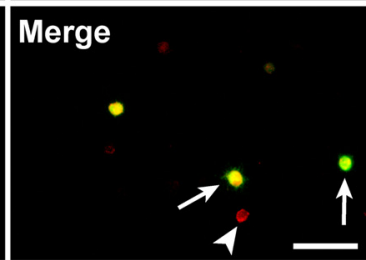

B

Fibronectin

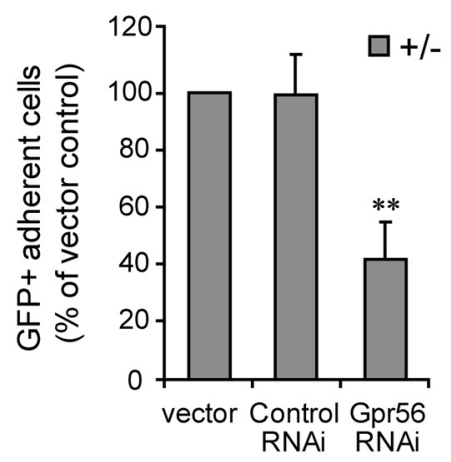

D

Fibronectin

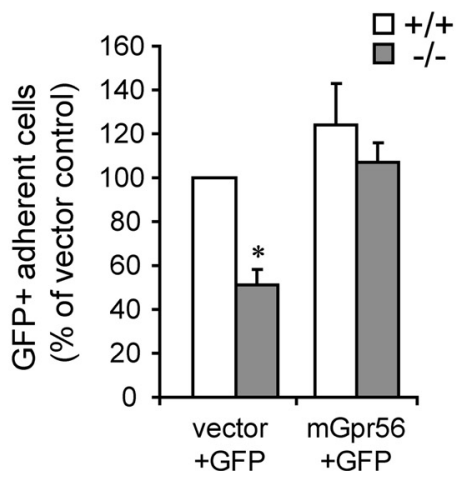

Laminin-1

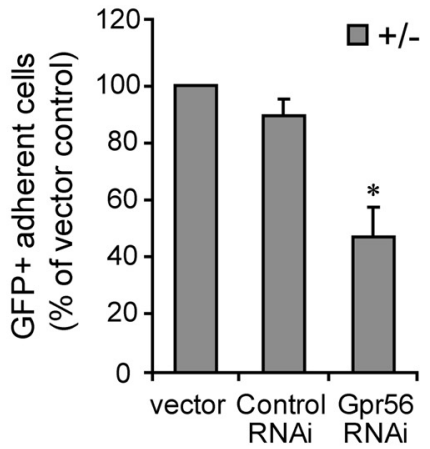

Figure 5. Loss- and gain-of-function studies confirm the role of GPR56 in granule cell adhesion. $\boldsymbol{A}, \boldsymbol{B}$, RNAi expression decreases GPR56 protein in GFP-positive electroporated cells ( $\boldsymbol{A}$, arrows) compared with surrounding cells without RNAi. Knockdown of GPR56 causes significant loss of adhesion to fibronectin and laminin- 1 in granule cells derived from the rostral region of Gpr $56^{+/-}$ organotypic cerebellar slices. C, D, Ex vivo electroporation of a tagged full-length GPR56 construct restores GPR56 expression in Gpr $56^{-/-}$granule cells, as visualized by immunostaining for the V5 tag (in red, arrows and arrowheads in C). EGFP is coelectroporated using a second plasmid, and occasionally a cell is seen with expression of V5 but not EGFP (arrowhead in C). Restoring GPR56 expression completely rescues the adhesion defect in $G p r 56^{-/-}$granule cells from the organotypic slices ( ${ }^{*} p<0.05$ in $\boldsymbol{B}$, right; ${ }^{* *} p<0.01$ in $\boldsymbol{B}$, left; ${ }^{*} p<0.05$ in $\boldsymbol{D}$; ANOVA; $n=4$ experiments for RNAi; $n=3$ experiments for GPR56 reexpression; $n=$ more than 3 slices per sample per experiment). Scale bar: (in $\boldsymbol{C}) \boldsymbol{A}, \boldsymbol{C}, 100 \mu \mathrm{m}$.

Gpr56 knock-outs indicate that GPR56 plays a critical role in the morphogenesis of the rostral cerebellum. Furthermore, GPR56 appears to perform this role by regulating adhesion of developing granule cells to ECM components of the pial BM. Loss of GPR56 in cerebellar granule cells results in fragmentation of the BM and disruption of Bergmann glial end feet. Because the cerebellum and its BM appear normal before E18.5, GPR56 seems to be dispensable for the initial formation of the rostral cerebellum but essential for its integrity during the perinatal period, when the rostral EGL undergoes rapid expansion.

Previous studies haves shown that integrity of the pial BM and glia limitans is critical for the morphogenesis of the cerebral and cerebellar cortices (Graus-Porta et al., 2001; Halfter et al., 2002; Moore et al., 2002; Beggs et al., 2003; Niewmierzycka et al., 2005; Belvindrah et al., 2007; Hu et al., 2007; Voss et al., 2008). Our results provide new appreciation of the potential role of neurons in the preservation of the cerebellar BM, with several lines of evidence suggesting that granule cells contribute to BM integrity through GPR56. First, at the critical time period when the BM defects arise in Gpr56 knock-outs, the only cells expressing GPR56 are developing granule cells (Bergmann glial expression appears later). Second, granule cells (but not glia) from the affected lobules in knock-outs show a specific loss of adhesion to $\mathrm{BM}$ molecules but no defects in proliferation, migration, and neurite outgrowth. Third, the loss of adhesion can be mimicked by knockdown of GPR56 in granule cells.

Electron microscopy of the EGL has shown that, during perinatal age, the glia limitans overlying the cerebellum is not yet continuous and that developing granule cells directly contact a substantial portion of the pial BM in between the glial end feet (Sievers et al., 1981). These direct contacts remain for some time postnatally even as granule cells begin their inward migration (Sievers et al., 1981; Hausmann and Sievers, 1985). The timing of these events raises the intriguing possibility that these granule cell-BM contacts may involve GPR56-mediated interactions. The possibility that granule cell-BM interactions are mediated by GPR56 is also supported by the observation that fluorescently tagged soluble GPR56 N-terminal peptides bind to the cerebellar BM and meninges (Li et al., 2008 and data not shown), suggesting that these structures contain a GPR56 ligand.

Our findings establish that GPR56 plays a role in regulating adhesion of cerebellar granule cells of the perinatal rostral cerebellum. Furthermore, based on our observations that exogenous GPR56 peptides and GPR56 expression in heterologous cells do not alter adhesion, GPR56 appears to contribute to cell adhesion indirectly rather than by directly binding to laminin-1 or fibronectin. The molecular interactors of GPR56 that may mediate its role in adhesion remain unknown. However, it is noteworthy 

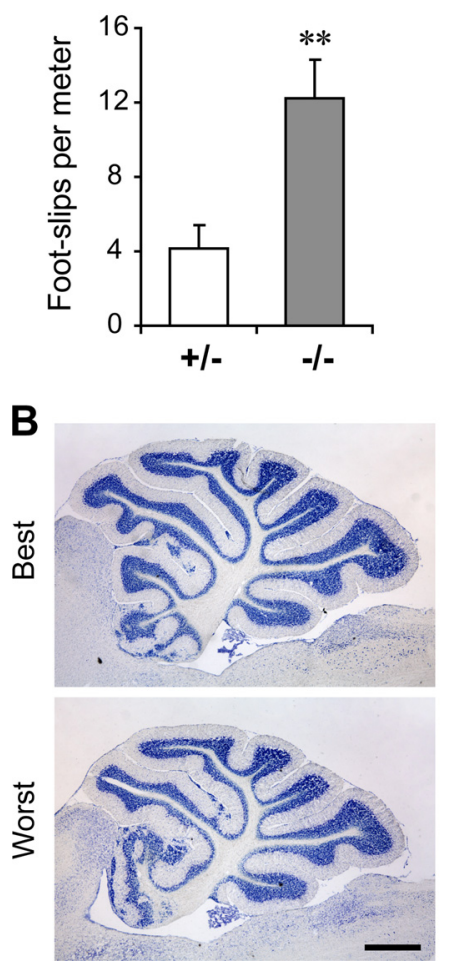

Beam walk time

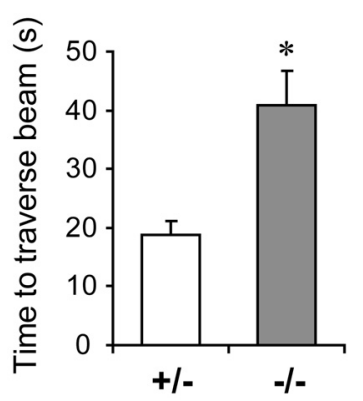

C

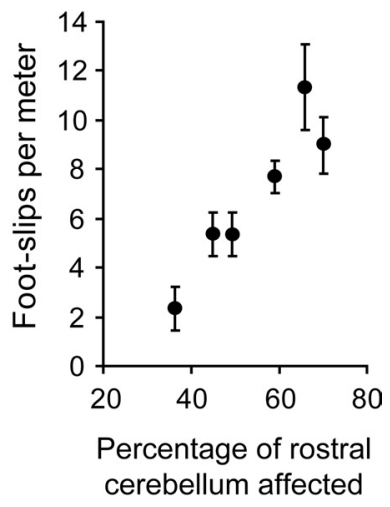

Figure 6. Motor coordination deficits in $G p r 56^{-/-}$mice. A, Gpr56 $6^{-/-}$mice perform poorly compared with heterozygotes when walking on a 4-mm-wide $\times 1$-m-long balance beam, displaying more foot slips $\left({ }^{* *} p<0.01\right)$ and taking longer to traverse it $\left({ }^{*} p<0.05 ; n=9\right.$ $G p r 56^{-1-}, 7 G p r 56^{+1-}$ ). Error bars represent \pm SEM. $p$ values from unpaired one-tailed Student's $t$ test. $\boldsymbol{B}, \boldsymbol{C}$, The severity of the cerebellar malformation correlates with the severity of the motor impairment. $\boldsymbol{B}$ shows midsagittal sections of the cerebella of the $G p r 56^{-1-}$ mice that performed best and worst in the balance beam test. Scale bar, $750 \mu \mathrm{m}$. The graph in $\boldsymbol{C}$ shows the relationship between the anatomical and motor defects of the $G p r 56^{-1-}$ mice (each point represents a single Gpr56 $6^{-1-}$ mouse that was tested in 3 trials, bars represent SEM).

that GPR56 associates with tetraspanins (Little et al., 2004), which in turn interact with integrins and other ECM binding proteins (Berditchevski and Odintsova, 1999; Yunta and Lazo, 2003), molecules known to contribute to the assembly, remodeling, and maintenance of BMs (Henry and Campbell, 1998; Schwarzbauer, 1999). Thus, GPR56 may play a role in BM integrity by interacting with some of these surface receptors. Although we have not found conclusive alterations in $G p r 56^{-1-}$ cerebella in the expression patterns of several key integrin subunits involved in laminin-1 and fibronectin binding, we cannot rule out other changes in integrins or the involvement of other adhesion molecules in the observed phenotypes.

The $G$ pr56 $6^{-/}$phenotypes in the developing forebrain ( $\mathrm{Li}$ et al., 2008) and the rostral cerebellum share significant features, including rupture of the pial BM, disorganization of the glial scaffold, and abnormal neuronal positioning. Together, these observations indicate that a key role of GPR56 in the brain is to maintain the integrity of the pial BM during expansion of the underlying cell layers. However, the cell types expressing GPR56 in the perinatal rostral cerebellum and embryonic cortex are different: developing neurons and radial glia, respectively. The distinctive role of granule cells in BM integrity may reflect the uniquely close association of these cells with the pial $\mathrm{BM}$ in the cerebellum.

Although ataxia is consistently observed in BFPP patients,

little is known about the characteristics of their cerebellar defects and the contribution of these to their motor symptoms. Our findings suggest that, in mice, the motor deficits are caused primarily by cerebellar abnormalities rather than defects in sensory or motor cortex or the pons and that the anterior cerebellum is preferentially affected. Our findings may have relevance to other human cerebellar malformations as well. For example, the defects we describe are reminiscent of cerebellar polymicrogyria, including the presence of ectopic granule cells, fusion of adjacent folia, misdirected Bergmann glial processes, and region-specific differences in severity (Aida et al., 1994; Demaerel et al., 1998; Patel and Barkovich, 2002; Soto-Ares et al., 2002). It would be interesting to examine whether GPR56 mutations or dysregulation play a role in some forms of cerebellar polymicrogyria.

The phenotype of Gpr56 $6^{-1-}$ mice sheds light on several key processes during cerebellar development. First, in these mice, many granule cells can be found in ectopic locations in the adult, supporting other evidence that these neurons can survive and mature without association with their normal neighboring cells (Blaess et al., 2004; Kerjan et al., 2005). Second, the outward migration of granule cells through breaches in the BM suggests that chemoattractive signals that may exist in the cerebellar anlage to guide granule cell migration inward (Borghesani et al., 2002) are in themselves insufficient to attract these cells in the absence of a viable pial barrier or that GPR56 is required for granule cells to respond to these signals. Third, our findings add to evidence that, despite the relatively uniform cellular architecture of the cerebellar cortex, there are developmentally critical molecular differences between regions, with some of these differences existing only transiently (Millen et al., 1995; Herrup and Kuemerle, 1997).

Although a number of mutant mice with disrupted cerebellar lamination and presence of ectopic neurons have been described, the phenotype produced by GPR56 loss of function has distinctive features. For example, the cerebella of mice lacking the genes for $\beta 1$-integrin (Graus-Porta et al., 2001; Blaess et al., 2004), dystroglycan (Moore et al., 2002), semaphorin-6A (Kerjan et al., 2005), or integrin-linked kinase (Belvindrah et al., 2006) share some key features in common with $G p r 56^{-1-}$ cerebella, including ruptures in the pial BM, disruptions of the glial scaffold, and presence of ectopic granule cells. However, in these mice, the defects occur throughout the cerebellum, whereas in $G p r 56^{-1-}$ mice, the defects are rostral specific. Whether the expression of any of these genes is affected only rostrally in the $\mathrm{Gpr}^{-1-} 6^{-1}$ cerebellum and could play a role in the Gpr $56^{-1-}$ phenotype merits additional study. There is a handful of mouse mutants in which the affected region is primarily rostral, for example, rostral cerebellar mutant $(\mathrm{rcm})$ (Ackerman et al., 1997; Eisenman and Brothers, 1998) and meander tail (mea) (Ross et al., 1990; Hawkes and Eisenman, 1997). However, the loss of Gpr56 leads to a cerebellar phenotype different from that of these mice. In the $\mathrm{rcm}$ mutant, defects in guidance cause some granule cells to be misrouted to the midbrain, whereas in Gpr56 $6^{-1-}$ mice, the mislocalization of granule cells is restricted to the cerebellum. Similarly, although the affected region in mea and Gpr56 knock-out mice is similar, the major defect in mea is the loss of rostrally located granule cells, whereas granule cell proliferation and overall numbers are unaffected in Gpr56 $6^{-/-}$mice.

The cerebellar phenotype in Gpr56 $6^{-/-}$mice is strikingly similar to those observed when the meninges overlying the cerebellum are ablated at birth using 6-hydroxydopamine (Sievers et al., 1985, 1994a; von Knebel Doeberitz et al., 1986). This raises the intriguing possibility that the meninges are necessary for GPR56 
function in rostral cerebellar development, potentially as a source of the GPR56 ligand. The finding that a putative GPR56 ligand is present in the meninges (Li et al., 2008 and data not shown) is consistent with this hypothesis.

In summary, we show that the orphan GPCR, GPR56, plays a novel role in regulating adhesion of developing neurons to BM components and is essential for pial integrity and proper development of the rostral cerebellum. These observations point to defects in cell adhesion as a potential mechanism underlying the anatomical abnormalities in BFPP patients. Given the critical role of GPR56 described here and its broad expression in neuronal precursors in other brain regions, it is possible that GPR56 mutations or dysregulation could underlie other congenital brain defects in addition to BFPP.

\section{References}

Ackerman SL, Kozak LP, Przyborski SA, Rund LA, Boyer BB, Knowles BB (1997) The mouse rostral cerebellar malformation gene encodes an UNC-5-like protein. Nature 386:838-842.

Aida N, Yagishita A, Takada K, Katsumata Y (1994) Cerebellar MR in Fukuyama congenital muscular dystrophy: polymicrogyria with cystic lesions. AJNR Am J Neuroradiol 15:1755-1759.

Beggs HE, Schahin-Reed D, Zang K, Goebbels S, Nave KA, Gorski J, Jones KR, Sretavan D, Reichardt LF (2003) FAK deficiency in cells contributing to the basal lamina results in cortical abnormalities resembling congenital muscular dystrophies. Neuron 40:501-514.

Belvindrah R, Nalbant P, Ding S, Wu C, Bokoch GM, Müller U (2006) Integrin-linked kinase regulates Bergmann glial differentiation during cerebellar development. Mol Cell Neurosci 33:109-125.

Belvindrah R, Graus-Porta D, Goebbels S, Nave KA, Müller U (2007) $\beta 1$ integrins in radial glia but not in migrating neurons are essential for the formation of cell layers in the cerebral cortex. J Neurosci 27:13854-13865.

Berditchevski F, Odintsova E (1999) Characterization of integrintetraspanin adhesion complexes: role of tetraspanins in integrin signaling. J Cell Biol 146:477-492.

Bjarnadóttir TK, Fredriksson R, Schiöth HB (2007) The adhesion GPCRs: a unique family of $G$ protein-coupled receptors with important roles in both central and peripheral tissues. Cell Mol Life Sci 64:2104-2119.

Blaess S, Graus-Porta D, Belvindrah R, Radakovits R, Pons S, LittlewoodEvans A, Senften M, Guo H, Li Y, Miner JH, Reichardt LF, Müller U (2004) $\beta 1$-integrins are critical for cerebellar granule cell precursor proliferation. J Neurosci 24:3402-3412.

Borghesani PR, Peyrin JM, Klein R, Rubin J, Carter AR, Schwartz PM, Luster A, Corfas G, Segal RA (2002) BDNF stimulates migration of cerebellar granule cells. Development 129:1435-1442.

Carter RJ, Lione LA, Humby T, Mangiarini L, Mahal A, Bates GP, Dunnett SB, Morton AJ (1999) Characterization of progressive motor deficits in mice transgenic for the human Huntington's disease mutation. J Neurosci 19:3248-3257.

Chang BS, Piao X, Bodell A, Basel-Vanagaite L, Straussberg R, Dobyns WB, Qasrawi B, Winter RM, Innes AM, Voit T, Grant PE, Barkovich AJ, Walsh CA (2003) Bilateral frontoparietal polymicrogyria: clinical and radiological features in 10 families with linkage to chromosome 16. Ann Neurol 53:596-606.

Demaerel P, Lagae L, Casaer P, Baert AL (1998) MR of cerebellar cortical dysplasia. AJNR Am J Neuroradiol 19:984-986.

Eisenman LM, Brothers R (1998) Rostral cerebellar malformation ( $\mathrm{rcm} /$ $\mathrm{rcm}$ ): a murine mutant to study regionalization of the cerebellum. J Comp Neurol 394:106-117.

Englund C, Kowalczyk T, Daza RA, Dagan A, Lau C, Rose MF, Hevner RF (2006) Unipolar brush cells of the cerebellum are produced in the rhombic lip and migrate through developing white matter. J Neurosci 26:9184-9195.

Graus-Porta D, Blaess S, Senften M, Littlewood-Evans A, Damsky C, Huang Z, Orban P, Klein R, Schittny JC, Müller U (2001) Beta1-class integrins regulate the development of laminae and folia in the cerebral and cerebellar cortex. Neuron 31:367-379.

Halfter W, Dong S, Yip YP, Willem M, Mayer U (2002) A critical function of the pial basement membrane in cortical histogenesis. J Neurosci 22:6029-6040.
Harbord MG, Boyd S, Hall-Craggs MA, Kendall B, McShane MA, Baraitser M (1990) Ataxia, developmental delay and an extensive neuronal migration abnormality in 2 siblings. Neuropediatrics 21:218-221.

Hausmann B, Sievers J (1985) Cerebellar external granule cells are attached to the basal lamina from the onset of migration up to the end of their proliferative activity. J Comp Neurol 241:50-62.

Hawkes R, Eisenman LM (1997) Stripes and zones: the origins of regionalization of the adult cerebellum. Perspect Dev Neurobiol 5:95-105.

Hearps AC, Pryor MJ, Kuusisto HV, Rawlinson SM, Piller SC, Jans DA (2007) The biarsenical dye Lumio exhibits a reduced ability to specifically detect tetracysteine-containing proteins within live cells. J Fluoresc 17:593-597.

Henry MD, Campbell KP (1998) A role for dystroglycan in basement membrane assembly. Cell 95:859-870.

Herrup K, Kuemerle B (1997) The compartmentalization of the cerebellum. Annu Rev Neurosci 20:61-90.

Hu H, Yang Y, Eade A, Xiong Y, Qi Y (2007) Breaches of the pial basement membrane and disappearance of the glia limitans during development underlie the cortical lamination defect in the mouse model of muscle-eyebrain disease. J Comp Neurol 502:168-183.

Iguchi T, Sakata K, Yoshizaki K, Tago K, Mizuno N, Itoh H (2008) Orphan G protein-coupled receptor GPR56 regulates neural progenitor cell migration via a $G$ alpha $12 / 13$ and Rho pathway. J Biol Chem 283:14469-14478.

Jin Z, Tietjen I, Bu L, Liu-Yesucevitz L, Gaur SK, Walsh CA, Piao X (2007) Disease-associated mutations affect GPR56 protein trafficking and cell surface expression. Hum Mol Genet 16:1972-1985.

Ke N, Sundaram R, Liu G, Chionis J, Fan W, Rogers C, Awad T, Grifman M, Yu D, Wong-Staal F, Li QX (2007) Orphan G protein-coupled receptor GPR56 plays a role in cell transformation and tumorigenesis involving the cell adhesion pathway. Mol Cancer Ther 6:1840-1850.

Ke N, Ma H, Diedrich G, Chionis J, Liu G, Yu DH, Wong-Staal F, Li QX (2008) Biochemical characterization of genetic mutations of GPR56 in patients with bilateral frontoparietal polymicrogyria (BFPP). Biochem Biophys Res Commun 366:314-320.

Kerjan G, Dolan J, Haumaitre C, Schneider-Maunoury S, Fujisawa H, Mitchell KJ, Chédotal A (2005) The transmembrane semaphorin Sema6A controls cerebellar granule cell migration. Nat Neurosci 8:1516-1524.

Li S, Jin Z, Koirala S, Bu L, Xu L, Hynes RO, Walsh CA, Corfas G, Piao X (2008) GPR56 regulates pial basement membrane integrity and cortical lamination. J Neurosci 28:5817-5826.

Little KD, Hemler ME, Stipp CS (2004) Dynamic regulation of a GPCRtetraspanin-G protein complex on intact cells: central role of CD81 in facilitating GPR56-Galpha q/11 association. Mol Biol Cell 15:2375-2387.

Millen KJ, Hui CC, Joyner AL (1995) A role for En-2 and other murine homologues of Drosophila segment polarity genes in regulating positional information in the developing cerebellum. Development 121:3935-3945.

Moore SA, Saito F, Chen J, Michele DE, Henry MD, Messing A, Cohn RD, Ross-Barta SE, Westra S, Williamson RA, Hoshi T, Campbell KP (2002) Deletion of brain dystroglycan recapitulates aspects of congenital muscular dystrophy. Nature 418:422-425.

Niewmierzycka A, Mills J, St-Arnaud R, Dedhar S, Reichardt LF (2005) Integrin-linked kinase deletion from mouse cortex results in cortical lamination defects resembling cobblestone lissencephaly. J Neurosci 25:7022-7031.

Parrini E, Ferrari AR, Dorn T, Walsh CA, Guerrini R (2008) Bilateral frontoparietal polymicrogyria, Lennox-Gastaut syndrome, and GPR56 gene mutations. Epilepsia. Advance online publication. Retrieved April 14, 2009. doi: 10.1111/j.1528-1167.2008.01787.x.

Patel S, Barkovich AJ (2002) Analysis and classification of cerebellar malformations. AJNR Am J Neuroradiol 23:1074-1087.

Piao X, Basel-Vanagaite L, Straussberg R, Grant PE, Pugh EW, Doheny K, Doan B, Hong SE, Shugart YY, Walsh CA (2002) An autosomal recessive form of bilateral frontoparietal polymicrogyria maps to chromosome 16q12.2-21. Am J Hum Genet 70:1028-1033.

Piao X, Hill RS, Bodell A, Chang BS, Basel-Vanagaite L, Straussberg R, Dobyns WB, Qasrawi B, Winter RM, Innes AM, Voit T, Ross ME, Michaud JL, Déscarie JC, Barkovich AJ, Walsh CA (2004) G proteincoupled receptor-dependent development of human frontal cortex. Science 303:2033-2036.

Piao X, Chang BS, Bodell A, Woods K, Benzeev B, Topcu M, Guerrini R, Goldberg-Stern H, Sztriha L, Dobyns WB, Barkovich AJ, Walsh CA 
(2005) Genotype-phenotype analysis of human frontoparietal polymicrogyria syndromes. Ann Neurol 58:680-687.

Ross ME, Fletcher C, Mason CA, Hatten ME, Heintz N (1990) Meander tail reveals a discrete developmental unit in the mouse cerebellum. Proc Natl Acad Sci U S A 87:4189-4192.

Schaeren-Wiemers N, Gerfin-Moser A (1993) A single protocol to detect transcripts of various types and expression levels in neural tissue and cultured cells: in situ hybridization using digoxigenin-labelled cRNA probes. Histochemistry 100:431-440.

Schwarzbauer J (1999) Basement membranes: putting up the barriers. Curr Biol 9:R242-R244.

Shashidhar S, Lorente G, Nagavarapu U, Nelson A, Kuo J, Cummins J, Nikolich K, Urfer R, Foehr ED (2005) GPR56 is a GPCR that is overexpressed in gliomas and functions in tumor cell adhesion. Oncogene 24:1673-1682.

Sievers J, Mangold U, Berry M, Allen C, Schlossberger HG (1981) Experimental studies on cerebellar foliation. I. A qualitative morphological analysis of cerebellar fissuration defects after neonatal treatment with 6-OHDA in the rat. J Comp Neurol 203:751-769.

Sievers J, Mangold U, Berry M (1985) 6-OHDA-induced ectopia of external granule cells in the subarachnoid space covering the cerebellum. III. Morphology and synaptic organization of ectopic cerebellar neurons: a scanning and transmission electron microscopic study. J Comp Neurol 232:319-330.

Sievers J, Pehlemann FW, Gude S, Berry M (1994a) A time course study of the alterations in the development of the hamster cerebellar cortex after destruction of the overlying meningeal cells with 6-hydroxydopamine on the day of birth. J Neurocytol 23:117-134.
Sievers J, Pehlemann FW, Gude S, Berry M (1994b) Meningeal cells organize the superficial glia limitans of the cerebellum and produce components of both the interstitial matrix and the basement membrane. J Neurocytol 23:135-149.

Soto-Ares G, Devisme L, Jorriot S, Deries B, Pruvo JP, Ruchoux MM (2002) Neuropathologic and MR imaging correlation in a neonatal case of cerebellar cortical dysplasia. AJNR Am J Neuroradiol 23:1101-1104.

Stühmer T, Anderson SA, Ekker M, Rubenstein JL (2002) Ectopic expression of the Dlx genes induces glutamic acid decarboxylase and Dlx expression. Development 129:245-252.

Sudarov A, Joyner AL (2007) Cerebellum morphogenesis: the foliation pattern is orchestrated by multi-cellular anchoring centers. Neural Dev 2:26

Sztriha L, Nork M (2000) Bilateral frontoparietal polymicrogyria and epilepsy. Pediatr Neurol 22:240-243.

von Knebel Doeberitz C, Sievers J, Sadler M, Pehlemann FW, Berry M, Halliwell P (1986) Destruction of meningeal cells over the newborn hamster cerebellum with 6-hydroxydopamine prevents foliation and lamination in the rostral cerebellum. Neuroscience 17:409-426.

Voss AK, Britto JM, Dixon MP, Sheikh BN, Collin C, Tan SS, Thomas T (2008) C3G regulates cortical neuron migration, preplate splitting and radial glial cell attachment. Development 135:2139-2149.

Xu L, Begum S, Hearn JD, Hynes RO (2006) GPR56, an atypical G proteincoupled receptor, binds tissue transglutaminase, TG2, and inhibits melanoma tumor growth and metastasis. Proc Natl Acad Sci USA 103:9023-9028.

Yunta M, Lazo PA (2003) Tetraspanin proteins as organisers of membrane microdomains and signalling complexes. Cell Signal 15:559-564. 